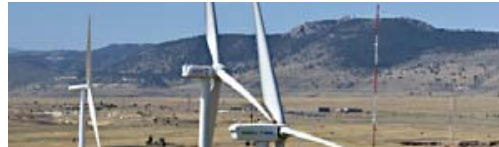

wWw.nrel.gov/wind

\section{Field Testing}

Independent, Accredited Testing and Validation

for the Wind Industry

NREL's specialized facilities and personnel at the National Wind Technology Center (NWTC) provide the U.S. wind industry with scientific and engineering support that has proven critical to the development of wind energy for U.S. energy needs. The NWTC's specialized field-testing capabilities have evolved over 30 years of continuous support by the U.S. Department of Energy Wind and Hydropower Technologies Program and long standing industry partnerships.

The NWTC provides wind industry manufacturers, developers, and operators with turbine and component testing all in one convenient location. Although industry utilizes sophisticated modeling tools to design and optimize turbine configurations, there are always limitations in modeling capabilities, and testing is a necessity to ensure performance and reliability. Designs require validation and testing is the only way to determine if there are flaws. Prototype testing is especially important in capturing manufacturing flaws that might require fleet-wide retrofits.

The NWTC works with its industry partners to verify the performance and reliability of wind turbines that range in size from 400 Watts to 3 megawatts. Engineers conduct tests on components and full-scale turbines in laboratory environments and in the field. Test data produced from these tests can be used to validate turbine design codes and simulations that further advance turbine designs.

\section{Accreditation}

As a facility accredited through the American Association of Laboratory Accreditation (A2LA) to perform several critical tests, the NWTC provides high quality testing to turbine manufacturers and wind plant developers, to enable them to meet requirements levied by wind turbine certification agencies, financial institutions, and other oversight organizations throughout the world. A2LA is an independent organization that audits and monitors all NWTC testing activities to ensure that sufficient quality control processes are followed to produce reliable test results. The NWTC is accredited to perform the following tests in accordance with international standards:

- Acoustic Noise to IEC 61400-11 and MEASNET

- Power Performance to IEC 61400-12-1 and MEASNET and deployment objectives.

- Mechanical Loads to IEC 61400-13

- Power Quality to IEC 61400-21 and MEASNET

- Duration Testing to IEC 61400-2

- Safety and Function to IEC 61400-2

NWTC field-testing staff are members of IEC (International Electrotechnical Commission) standards committees for Power Performance (MT12-1, MT12-2), Noise (MT-11), Loads (MT13), and Power Quality (MT21) testing; are also members of the international Measuring Network of Wind Energy Institutes (MEASNET) field-test proficiency and

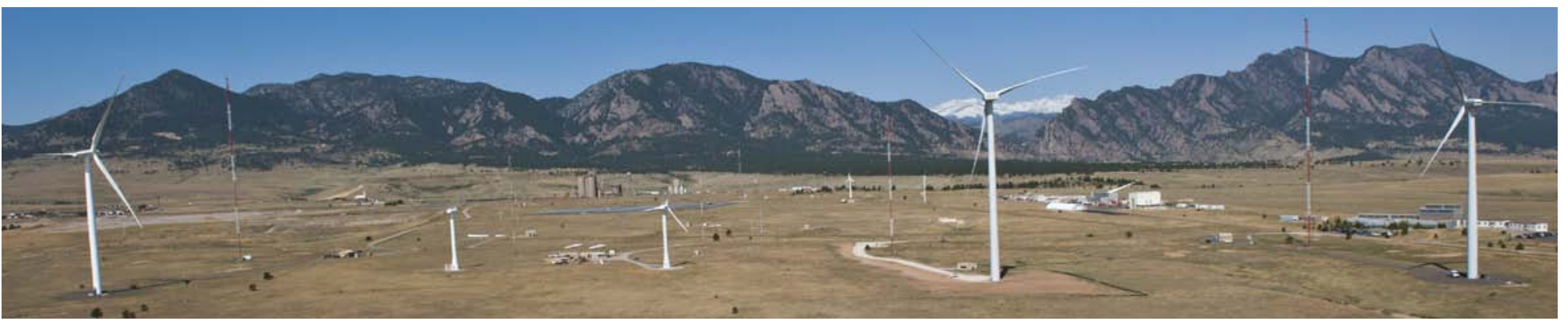


procedures development committee; and additionally are on the AWEA (American Wind Energy Association) small turbine safety and performance committee. Small wind turbines tested at the NWTC include Abundant Renewable Energy's ARE 442, Bergey's Excel, Entegrity Wind Systems' EW50, Gaia-Wind's 11 kW, Mariah Power's Windspire, Southwest Wind Power's Skystream and Whisper H40, Northern Power System's Northwind 100B, Ventera's VT10, and Windward Engineering's Endurance.

Tests include turbine structural dynamic characterization testing and model testing. In addition, NWTC conducts many tests that support turbine R\&D, most notably the NREL Unsteady Aerodynamics Experiment in the NASA-Ames Wind Tunnel: A Comparison of Predictions to Measurements that acquired data sets for more than 1,700 different turbine conditions. The data collected are a valuable resource for developing and validating wind turbine aerodynamic codes.

\section{Test Pads}

Manufacturers use test pads located at the NWTC to test their prototype and commercial machines that range in size from 400 Watts to 3 megawatts. In addition to the small wind turbines previously listed, four multi-megawatt test turbines at the NWTC include Alstom's 3 MW Eco100, Gamesa's 2 MW G97, GE's 1.5 MW, and Siemens 2.3 MW commercial turbines. The Alstom turbine will undergo a series of certification tests and drive train modeling tests and validation. At a hub height of 90 meters and a rotor diameter of 97 meters, the Gamesa turbine is part of an agreement between NREL and Gamesa to conduct research, development, and testing. The DOE-owned

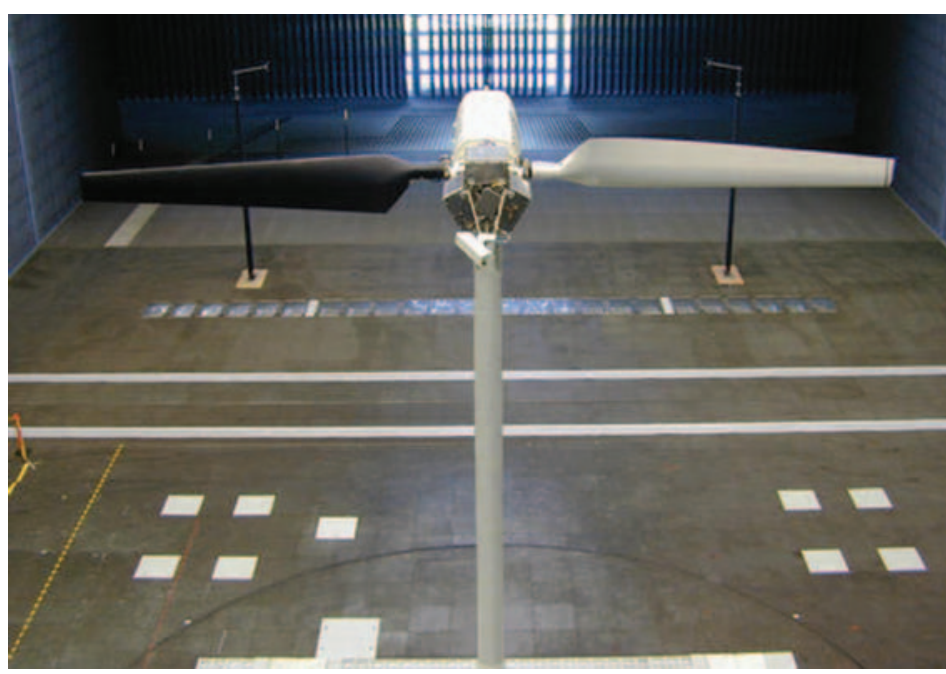

The heart of the Unsteady Aerodynamic Experiment conducted at NASA is the pressure measurement system installed in the black blade of the turbine. Photo by Lee Jay Fingersh, NREL/PIX 09998

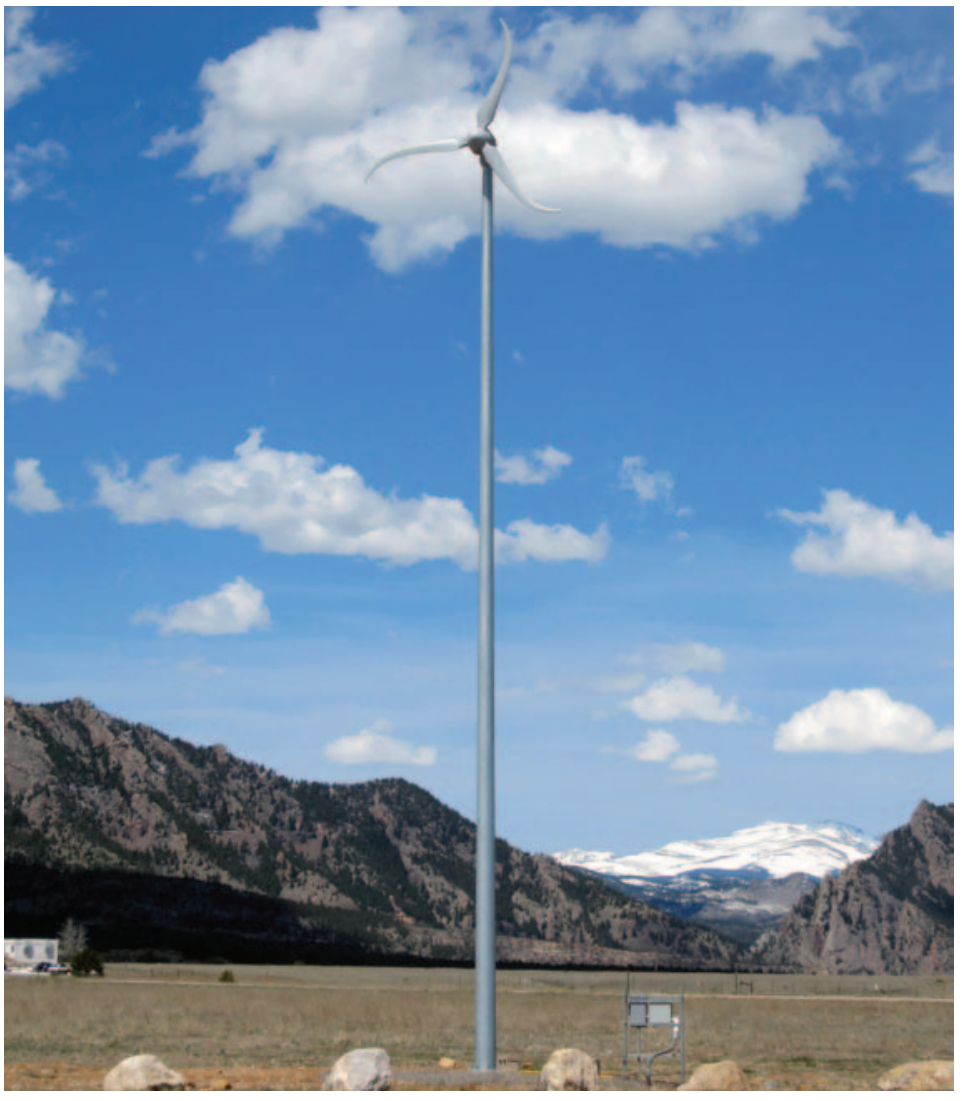

The Southwest Windpower Skystream 3.7 wind turbine rated at 2.4 $\mathrm{kW}$, with a blade diameter of 3.7 meters, and mounted on a 10-meter monopole. Photo by Lee Jay Fingersh, NREL/PIX 16384

GE 1.5 MW turbine provides long-term testing and is an R\&D tool. It is instrumented to collect detailed data on wind farm underperformance and premature turbine component failure. In addition, it is used for educational and outreach purposes. The Siemen's $2.3 \mathrm{MW}$ turbine is a late-stage prototype. It is heavily instrumented to produce a constant stream of data on aerodynamics, power characteristics, vibrations, system fatigue, acoustics, and other key measurements.

For more information about the NWTC's field testing capabilities, contact the National Wind Technology Center at 303-384-6900.

\section{Helpful Web Sites}

The National Wind Technology Center

www.nrel.gov/wind

Department of Energy Wind Power Program www.wind.energy.gov

\section{Front page header, L to R: Photo by Dennis Schroeder, NREL/PIX 19007; Photo by Lee Jay Fingersh, NREL/PIX 15005; Photo by Warren Gretz, NREL/PIX 12415; Photo by Lee Jay Fingersh, NREL/PIX 14691; Photo by Dennis Schroeder, NREL/PIX 18937}

National Renewable Energy Laboratory

1617 Cole Boulevard, Golden, Colorado 80401

303-275-3000 • www.nrel.gov
NREL is a national laboratory of the U.S. Department of Energy Office of Energy Efficiency and Renewable Energy Operated by the Alliance for Sustainable Energy, LLC

NREL/FS-5000-52967 • November 2011 